\title{
Niños y niñas nacidos con síndrome de Down: Historias de vida de padres y madres
}

\author{
Children with Down Syndrome: Life Stories of Parents
}

\author{
Maritza Esquivel-Herrera' \\ Centro Nacional de Educación Especial Fernando Centeno Güell \\ San José, Costa Rica \\ maritzaesquivel@yahoo.com.mx
}

Recibido 27 de octubre de 2014 • Corregido 1 de noviembre de 2014 • Aceptado 22 de noviembre de 2014

\begin{abstract}
Resumen El presente artículo parte de la premisa de que la estimulación temprana se constituye en el programa propicio para iniciar la atención y educación integral de niños y niñas recién nacidos que presentan síndrome de Down, con el objetivo prioritario de desarrollar al máximo sus capacidades cognitivas, físicas y socioemocionales. Con ese propósito, se trabajó con un paradigma naturalista y un enfoque descriptivo tipo caso, con priorización de datos cualitativos, referidos a las historias de vida de padres y madres de familia que han procreado a un niño o niña con este síndrome. Participaron miembros de familias ( 9 madres y un padre) y su intervención fue de carácter voluntaria. Se utilizaron como instrumentos la recopilación de historias de vida, apoyados en entrevistas realizadas a los padres y madres de familia, y sistematizadas mediante el instrumento de la crónica. También se utilizó un instrumento de frases u oraciones incompletas, que buscó conocer las impresiones más profundas que los padres y madres de familia experimentaron, antes y después del nacimiento de un hijo o hija con dicho síndrome. Se busca que los planteamientos expresados sirvan de apoyo a quienes tienen en su vida cotidiana situaciones similares a la expuesta y, específicamente, que repercutan en el aprovechamiento del tiempo para el desarrollo integral de la población infantil con esta condición.
\end{abstract}

Palabras claves. Síndrome de Down, historias de vida, estimulación temprana, educación.

\footnotetext{
${ }^{1}$ Licencianda en Retos Múltiples de la Universidad de Costa Rica, docente universitaria de la carrera de Educación Especial de la Universidad Nacional y docente del Centro Nacional de Educación Especial Fernando Centeno Güell, con experiencia profesional en el campo de la estimulación temprana y retos múltiples.
} 
doi: http://dx.doi.org/10.15359/ree.19-1.17

URL: http://www.una.ac.cr/educare

CORREO: educare@una.cr

\begin{abstract}
This paper is based on the premise that early stimulation is the appropriate program to start the integral care and education of newborns with Down Syndrome, with the primary objective being to optimize their cognitive, physical and socio-emotional capabilities. For this purpose, a naturalist paradigm and a descriptive case type approach were used, mainly with qualitative data related to the life stories of parents with Down Syndrome children. Parents ( 9 mothers and one father) participated voluntarily in the research project. One of the instruments used was the compilation of life histories, which were collected though interviews to parents and were systematized in the form of chronicles. Another instrument was phrases or sentences to fill in the blanks, which were used to know the deepest impressions experienced by parents before and after the birth of their Down Syndrome child. This paper is intended to provide support to those who experience daily situations similar to the ones mentioned here and, particularly to impact on the time management in the integral development of children with this condition.
\end{abstract}

Keywords. Down Syndrome, life stories, early stimulation, education.

En Costa Rica el Centro de Registro de Enfermedades Congénitas (CREC) registra o recopila los reportes sobre anomalías y síndromes de la población infantil. Barboza-Argüello y UmañaSolís (2008), en un estudio realizado, señalan que las anomalías congénitas son la segunda causa de mortalidad infantil y en primer lugar se encuentran los problemas perinatales. Agregan las autoras que en el período 1996-2005, fueron reportados en el país 703 casos de niños y niñas nacidas con síndrome de Down, de los cuales sobrevivieron 694.

El síndrome de Down, dentro de sus particularidades, implica un retraso o limitación a nivel de desarrollo, lo cual repercute en las expectativas de cualquier padre y madre de familia, cuyo deseo más genuino es traer al mundo niños y niñas sanos, lo cual, ante el nacimiento de un hijo o hija, con malformaciones o síndromes, afecta sus anhelos antes de dicho nacimiento, aspecto que no es igual para quienes reciben en su hogar una niña o niño sano.

Cruz, Camacho, Rivera y Saborío (1985) realizaron, en Costa Rica, un estudio sobre la trisomía 21 que es una de las afecciones de algunos síndromes de Down y con el análisis retrospectivo de 658 casos entre 1971 y 1982, encontraron que 1 de cada 269 niños o niñas que ingresaba al Hospital Nacional de Niños por alguna complicación en su salud durante el primer año de vida, era portador de trisomía 21. Los autores concluyen que la trisomía 21 tiene una explicación multicausal y destacan dentro de los factores posibles, la edad de los padres y madres, la situación socio-económica, la dieta, el uso de anticonceptivos, época del año y lugar de residencia. Aspectos que a criterio personal, podrían estar presentes en cualquier familia costarricense, por lo que es posible que muchas veces los padres y madres tengan la expectativa de recibir un recién nacido saludable y no un niño o niña con síndrome de Down. 
Como profesora de estimulación temprana he conocido padres y madres de infantes con síndrome de Down, quienes por primera vez asumen el reto de enfrentarse a una sociedad que aún no está preparada para atender la diversidad, un poco temerosos y ansiosos se acercan al Centro de Educación Especial, esperando se les oriente sobre cómo estimular a sus hijos e hijas; sin embargo, la mayoría de estos padres y madres experimentan un sin fin de sentimientos que, aunque como docente logro comprender, no es, sino hasta que se establece una red de apoyo entre ellos mismos, que entienden que los sentimientos no son propios de ellos, sino que, de una u otra forma, la mayoría de los padres y madres de esta población con discapacidad ha pasado por esa etapa.

Vivenciando, día a día, este encuentro de sentimientos es que he logrado recopilar las historias de vida de varios padres y madres de familia, quienes ante el nacimiento de su hijo o hija con síndrome de Down, sintieron tristeza, temor, angustia, alegría, entre muchos otros sentimientos y emociones. Estas familias han decidido compartir su experiencia y, por este medio, procurar apoyar a otros padres y madres que se enfrentan por vez primera ante el reto de atender tempranamente y en forma integral a estos menores con síndrome de Down. De modo que el artículo busca ofrecer al lector y lectora, las historias de vida de padres y madres de niños y niñas nacidas con síndrome de Down y, desde la visión de la autora, destacar la importancia de la atención integral temprana para poblaciones con esta característica.

\section{Contextualización teórica}

En el presente apartado, se hace una breve revisión teórica que permite enmarcar la temática y acercar al lector y lectora a los planteamientos que, en cuanto al síndrome de Down y la estimulación temprana, son importantes de tener en consideración para comprender y aprovechar las experiencias aportadas por las historias de vida que comparten padres y madres de familia costarricenses.

\section{Estimulación temprana}

En los primeros años de vida, el cerebro evoluciona de manera sorprendente, permitiendo conexiones neuronales para establecer las bases para futuros aprendizajes y potenciar el desarrollo de las diferentes áreas.

De la adaptación del recién nacido al mundo depende su óptimo desarrollo, por lo cual la estimulación temprana es un medio idóneo para favorecer el avance integral de los recién nacidos.

Según De Narvaez (2008), la estimulación temprana es"toda aquella actividad de contacto o juego con un bebé o un niño que propicie, fortalezca y desarrolle adecuada y oportunamente sus potenciales humanos" (párr. 1). 
doi: http://dx.doi.org/10.15359/ree.19-1.17

URL: http://www.una.ac.cr/educare

CORREO: educare@una.cr

Esta tiene como objetivo desarrollar al máximo el potencial de cada infante, para incrementar su desarrollo físico, cognitivo y lingüístico; sus habilidades sociales y sus capacidades de autonomía personal, con lo cual facilita la formación de nuevas conexiones neuronales, a la vez, previene necesidades educativas en infantes nacidos prematuramente, o con riesgos en el momento del parto. También favorece el vínculo afectivo entre padres e hijos y reduce las tensiones familiares.

Desde el campo de la educación especial y basada en mi experiencia de trabajo en programas costarricenses de estimulación temprana para población infantil con síndrome de Down, comparto la idea de Terré (2005), al hablar de la estimulación temprana como un modelo en el cual se entrena al niño y a la niña para garantizar éxito en la vida escolar.

Dentro de un programa de estimulación temprana, los padres y madres se constituyen en el eje fundamental, ya que son ellos quienes, con la guía del personal docente, desarrollan el plan de trabajo, pues el contacto diario familia-infante es indispensable para desarrollar el vínculo afectivo; además permite valorar los esfuerzos y logros de sus hijos e hijas e iniciar el proceso educativo de los menores.

Sin embargo, muchas veces este inicio se ve retrasado por la forma en que los padres y madres de familia recibieron la noticia de la condición que presenta su hijo o hija, ya que aún encontramos quienes creen que, al haber una condición de discapacidad, la persona no es capaz de desempeñarse en la sociedad y ser autónoma e independiente.

Permanecen en nuestra sociedad barreras actitudinales que limitan la plena participación de la persona en condición de discapacidad, pues como se ha visto muchas veces, no se experimentan a nivel contextual acciones de comprensión hacia la persona con síndrome de Down y, en ocasiones, tal como lo señalan las historias de vida, existe desconocimiento sobre la condición de este síndrome. Esta situación, aunada al sin fin de sentimientos y emociones por los que pasan las familias ante la noticia del nacimiento de un miembro con discapacidad, podrían ser factores que lleven a obstaculizar el inicio del proceso educativo para niños y niñas con síndrome de Down limitando la estimulación temprana de sus habilidades y destrezas.

Los talleres para padres y madres, que se realizan en el programa de estimulación temprana, se constituyen en una herramienta importante para los docentes en el campo de la educación especial, sobre todo en el nivel de estimulación temprana, pues en estos es posible llevarlos a compartir sus historias de vida, lo cual les permite reconocer que no están solos, que hay otras personas con un recién nacido con síndrome de Down.

Dichos talleres brindan información a los padres y madres de familia sobre la condición de discapacidad y, sobre todo, ayudan a los padres y madres a conocer la manera como apoyar el trabajo educativo que se realiza con sus hijos e hijas desde el hogar; además, le permite al 
personal docente conocer la fase en la que se encuentran los padres o madres ante la noticia de la condición de discapacidad de su hijo o hija, de manera que pueda buscar las redes de apoyo que cada familia necesita para lograr el éxito en el proceso educativo que inician.

\section{Síndrome Down}

Antes de tener un hijo o hija con síndrome de Down o de trabajar con población con esta condición, es probable que los padres y madres de familia no hayan centrado su interés en el conocimiento de esta temática, o incluso, hayan escuchado poco acerca de esta.Uno de los planteamientos acerca del origen del síndrome de Down plantea que quien lo presenta en su estructura genética posee un cromosoma adicional. En ese sentido, en su organismo se cuantifican 47 cromosomas y no 46 como es lo habitual. Lo pueden presentar hombres o mujeres en igual proporción. Según Kozma (1998), el síndrome de Down es una de las condiciones congénitas que con frecuencia puede estar presente en poblaciones diversas por lo que es una condición que responde a causas multifactoriales.

Cuando aparece un cromosoma adicional, se desequilibra el orden cromosómico y por ende, se pueden encontrar factores que afectan el crecimiento y el desarrollo infantil.

Los recién nacidos con síndrome Down presentan rasgos típicos en su rostro, cuello, manos y pies. Su tono muscular está disminuido (hipotonía) y el grado de discapacidad cognitiva varía de un individuo a otro; sin embargo, no debe olvidarse que cada persona es única, afirma Kozma (1998) que por eso los rasgos físicos de niños con dicho síndrome son similares de un bebé a otro; aunque también hay bebés que se asemejan a sus padres, madres y hermanos, por lo que, en ocasiones, los progenitores, que anticipadamente no conocían de la situación médica del hijo o hija por nacer, se sienten quizá abrumados por la situación.

Ante el nacimiento de un bebé con síndrome de Down, la familia no solo comienza a conocer sobre dicha condición, sino que también vivencia una serie de sentimientos y emociones que son esperables ante tal acontecimiento.

A continuación se presenta un apartado sobre las diferentes reacciones que pueden vivir los padres y las madres ante el nacimiento de un recién nacido con síndrome de Down.

\section{Reacciones iniciales de los progenitores}

Al nacer una persona con síndrome de Down, la familia se enfrenta a una serie de emociones ya que habitualmente no se espera la noticia de dicha condición, por lo que no hay un proceso previo de preparación para el ajuste emocional que se vive ante tal acontecimiento; vendrán muchas interrogantes y temor hacia el futuro; muchos padres y madres pueden enfrentarse a la 
doi: http://dx.doi.org/10.15359/ree.19-1.17

URL: http://www.una.ac.cr/educare

CORREO: educare@una.cr

situación, con un sentimiento de dolor; es este, en muchas ocasiones, la primera reacción ante la noticia del nacimiento del hijo o hija con síndrome de Down. Campabadal (2007) señala una serie de fases que enfrentan los padres y madres ante el nacimiento de un hijo o hija con discapacidad.

Cabe recordar que el diccionario de la Real Academia Española (2012) define la emoción como la "alteración del ánimo intensa y pasajera, agradable o penosa, que va acompañada de cierta conmoción somática," y el sentimiento como el "estado afectivo del ánimo producido por causas que lo impresionan vivamente. Estado del ánimo afligido por un suceso triste o doloroso."

A continuación se detallan las fases que, de acuerdo con su criterio, pueden enfrentar las familias ante el nacimiento de un niño o niña con síndrome de Down.

- La negación: es una fase en la que se pueden observar manifestaciones de tristeza, angustia, preocupación e incertidumbre, la forma en que los progenitores reciban la noticia será un factor importante en la actitud que asuman, ante la llegada a sus vidas de una persona con discapacidad.

- Miedo y frustración: en esta fase muchos padres y madres se preocupan por buscar la causa del porqué su hijo o hija nació con síndrome de Down, de ahí que, algunas veces, se rechaza al bebé o se le sobreprotege, disminuyendo la posibilidad de ofrecerle las condiciones contextuales necesarias para promover su desarrollo y realización como persona.

- Manipulación: en ocasiones los progenitores se valen de la discapacidad de su hijo o hija para satisfacer sus propios intereses. Por lo que es posible identificar en la dinámica familiar acciones manipulativas a raíz de la presencia de un bebé con síndrome de Down.

- Depresión: los padres y madres que afrontan esta fase, a raíz de la llegada de un hijo o hija con síndrome de Down suelen experimentar sentimientos negativos; sin embargo, esta fase suele ser el inicio de un proceso de ajuste ante la discapacidad.

- Aceptación: se evidencia en esta fase cómo los padres y madres han llegado a un nivel de mayor estabilidad, enfocándose no en la discapacidad, sino en buscar apoyos y soluciones alternativas tratando de integrar a su hijo o hija en los diversos contextos donde se desenvuelven, fomentando la autonomía e independencia. Es en este momento cuando suelen acercarse a instancias o centros educativos en busca de opciones para la atención de sus recién nacidos.

Todos estos sentimientos descritos anteriormente son esperados y disminuirán con el tiempo, para dar paso al disfrute de la alegría que significa tener en casa un recién nacido. 
Según Kawage (2000), lo más importante es"asumir el proceso que requiere la aceptación de esa situación en pro de las necesidades especiales del niño, de su educación y por la salud psicológica y social de los padres y de toda la familia" (p. 18).

Los padres y madres de familia, una vez recibido el diagnóstico de síndrome de Down en su hijo o hija, se enfrentan a la necesidad de asumir esa condición y, muchas veces, el proceso de aceptación inicia cuando se acercan a un centro de educación especial con el propósito de brindar mejor atención para la estimulación de cada infante y procurarle contextos de mayor desarrollo para sus capacidades.

La mejor opción que en ese momento se les puede ofrecer es acercarlos a un programa de estimulación temprana que se dirige a menores de 0 meses hasta los 3 años de edad.

Estos programas, además de ofrecerles al niño y a la niña nacidos con síndrome de Down, el beneficio de sesiones de estimulación, les brindan sesiones de terapia física y de lenguaje que, en conjunto, potenciarán el máximo desarrollo de las capacidades. A la vez, los padres y madres reciben talleres en donde se aclaran sus dudas y se les facilita la información necesaria para comprender la condición de discapacidad, y se les brindan estrategias educativas para mediar el aprendizaje de su hijo o hija desde el hogar.

Siendo parte del trabajo diario en clases de estimulación temprana, he logrado conocer las historias de vida de muchos padres y madres. Hemos compartido un sinfín de sentimientos y emociones ante la noticia de la discapacidad y, gracias a esa oportunidad, mediante este artículo, se retoman relatos familiares que, desde la perspectiva de los padres y madres de familia, les hicieron posible acudir a programas de educación temprana para sus hijos e hijas nacidas con síndrome de Down.

\section{Metodología}

\section{Tipo de estudio}

El estudio realizado se enmarcó en un paradigma naturalista y tuvo un enfoque descriptivo tipo caso, con priorización de datos cualitativos, referidos a las historias de vida de padres y madres de familia que han procreado a un niño o niña con síndrome de Down.

El propósito fue sistematizar y compartir las vivencias, mediante historias de vida, de padres y madres que experimentaron el nacimiento de una persona con discapacidad. Se espera que estas sirvan de apoyo a otras familias que enfrenten situaciones similares. 
doi: http://dx.doi.org/10.15359/ree.19-1.17

URL: http://www.una.ac.cr/educare

CORREO: educare@una.cr

\section{Participantes}

Se contó con la participación de miembros de familias (9 madres y un padre), su intervención fue de carácter voluntaria y firmaron el consentimiento informado de todos y todas, ya que el objetivo del estudio era, no solo conocer sus experiencias, sino poder compartir sus historias de vida y para que se constituyeran en incentivo y soporte de nuevas familias con situaciones similares, para que puedan animarse a brindar a sus hijos e hijas la atención temprana requerida.

\section{Instrumentos}

Se recurrió al uso de dos instrumentos cortos que buscaban recopilar las reacciones y primeras impresiones que los padres y madres de familia participantes vivenciaron ante el nacimiento de un hijo o hija con síndrome de Down, así como indagar acerca de los conocimientos que las familias tenían acerca de dicho síndrome y las acciones de atención temprana que les brindaron a sus hijos e hijas con esa condición.

El primero, se refiere a la recopilación de historias de vida, apoyado en entrevistas realizadas a los padres y madres de familia y sistematizadas mediante el instrumento de la crónica, que buscó recopilar las primeras reacciones, sentimientos y emociones experimentados por las familias al momento de conocer la noticia del nacimiento de sus hijos e hijas, con la condición de presentar síndrome de Down.

El segundo fue un instrumento de frases u oraciones incompletas que buscó conocer las impresiones más profundas experimentadas por los padres y madres de familia, antes y después del nacimiento de un hijo o hija con síndrome de Down.

Para este instrumento se utilizaron frases que buscaban complementar la información aportada por padres y madres en las historias de vida recopiladas previamente. Señala Pereira (2012) que las oraciones incompletas permiten a quien investiga"obtener respuestas cargadas de emotividad, pues por su forma de aplicación buscan que quien conteste, evoque sus recuerdos más profundos y de manera rápida, conteste con la primera idea que llegue a su mente" (p. 119).

La información aportada por ambos instrumentos fue transcrita de manera textual y organizada por fases, para identificar los elementos semejantes y divergentes experimentados por las distintas familias ante el nacimiento de sus hijos o hijas con síndrome de Down, expresados mediante las oraciones incompletas.

Una vez transcrita la información, se organizó en categorías de análisis, derivadas de las temáticas abordadas, a saber: reacciones iniciales (sentimientos y emociones) ante el nacimiento de un hijo o hija con síndrome de Down, conocimientos previos acerca de dicho síndrome y acciones tomadas por las familias para la atención temprana de sus hijos e hijas en esa condición y apoyos externos recibidos por las familias. 
De igual manera, cabe aclarar que, en aras de proteger la identidad de las personas participantes, los nombres de los padres y madres han sido sustituidos expresamente al utilizar el código de participante y un número para cada uno de ellos y ellas.

\section{Resultados}

\section{Reacciones iniciales ante el nacimiento de un hijo o hija con síndrome de Down}

De acuerdo con los sentimientos y emociones que enfrentan los padres y madres ante el nacimiento de un hijo o hija con discapacidad, se hace evidente la fase del miedo y la frustración. En las siguientes historias de vida, se identifican constantes cuestionamientos internos en los progenitores, quienes buscan explicaciones y culpables ante el nacimiento de la persona con síndrome de Down. A la vez, se rescata el papel fundamental que desempeñan los médicos en el proceso de ajuste que vivirán los padres y madres ante la noticia de la presencia de una discapacidad en sus hijos e hijas. Se destacan algunas expresiones que ilustran lo dicho.

\section{Participante 1:}

Cuando J. nació y me dijeron al día siguiente que tenía síndrome de Down, lloré mucho porque pensé que yo y mi esposo habíamos sido los culpables, ya después cuando el genetista y los libros me explicaron que era un accidente genético me sentí liberada de la culpa, pero no así de la depresión, de saber que la gente lo iba a ver como bicho raro y los compañeros se iban a burlar de él, y un montón de ridiculeces más, que ahora que recuerdo me dan risa de haber sido tan tonta y exagerada.

Un buen doctor me dio un excelente consejo: da un paso a la vez y del tamaño de sus pasitos. No pretendas resolverle los problemas universitarios, si apenas acaba de abrir los ojos.

Vale la pena destacar que en este caso particular, el sentimiento de "culpabilidad" fue el primero que apareció, pero a partir de la participación de un profesional médico y de la disposición a la búsqueda de información por parte de los progenitores, fue posible que ese sentimiento fluyera hacia la liberación de la culpa y hacia una actitud más positiva frente a la situación vivida.

\section{Participante 2:}

En el momento en que me dieron la noticia lo que sentí fue impotencia, miedo, preocupación, a pesar de que el doctor nos dio la noticia de la mejor manera y nos dijo de la siguiente forma: su hija está en neonatología porque se puso moradita por falta de oxígeno, tiene todas las características de tener síndrome de Down y un hueco en el corazón, en ese momento lo que más me impresionó fue lo del corazón, que gracias a Dios ya se le cerró, luego otro médico me 
doi: http://dx.doi.org/10.15359/ree.19-1.17

URL: http://www.una.ac.cr/educare

CORREO: educare@una.cr

recomendó hacerle el cariotipo (para saber el tipo de síndrome de Down) que inicialmente yo creía que era para saber si tenía o no síndrome de Down, se lo hice en INISA, donde una doctora me explicó por qué se da genéticamente, qué tipos hay y cuál tenía ella, entre otras cosas.

En el caso del participante 2, es interesante notar que los sentimientos que prevalecieron ante el nacimiento de su bebé con síndrome de Down fueron la impotencia, miedo y preocupación.

Como se nota a continuación, el apoyo recibido por profesionales, médicos o de educación especial, al igual que en el primer caso, fueron importantes en la historia de vida de este participante, sus palabras así lo confirman.

Luego una maestra en educación especial nos recomendó que la lleváramos a una escuela de enseñanza especial y fue así como a los 25 días de nacida ingresó a una institución de educación especial...

Ahora ese sentimiento de impotencia ya pasó, ya que cada logro de ella lo siento como uno mío por más pequeño que este sea y porque tengo mis metas muy claras que son seguirla sacando adelante, que sea lo más independiente posible y lograr que sea integrada a la sociedad como hasta ahora lo he hecho.

Por eso un niño especial es una bendición y como alguien me dijo, es una estrellita que bajó del cielo para que la cuidáramos y así se quede con nosotros.

Cuando una pareja espera el nacimiento de su hijo o hija, generalmente no se ha planteado la presencia de una discapacidad, pero en ocasiones el nacimiento del bebé en condición de discapacidad hace que sus expectativas se vean amenazadas, lo que genera sentimientos y emociones de dolor, tristeza y rechazo. La siguiente historia de vida nos ejemplifica los sentimientos de negación, miedo y depresión y las anteriores también.

\section{Participante 3:}

La llegada de mi bebé fue muy linda pero la noticia de su discapacidad fue como si el mundo se me viniera encima, lloré mucho y se lo oculté a mi esposo hasta el siguiente día cuando le pedí a un médico que le dijera porque yo no podía hacerlo, él me ayudó a salir de la depresión ya que él fue muy comprensivo, vimos a nuestro hijo como un regalo de Dios y no como un castigo y a Dios gracias hemos salido adelante y cada día que pasa las cosas cambian pero para bien del niño como para nosotros ya que lo amamos y él es la felicidad de la casa.

Ante el abanico de sentimientos y emociones que evidencian las familias al recibir la noticia de la discapacidad, las siguientes historias demuestran una mayor estabilidad en la familia, en donde se han dejado de lado la impresiones mayormente dolorosas, para buscar los apoyos necesarios para contribuir en el desarrollo de habilidades y destrezas de sus hijos e hijas. 


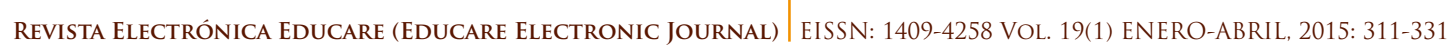

doi: http://dx.doi.org/10.15359/ree.19-1.17

URL: http://www.una.ac.cr/educare

CORREO: educare@una.cr

\section{Participante 4:}

Al recibir la noticia ambos estábamos muy asustados, primero porque viniera con alguna deficiencia física o porque no sobreviviera. Todo esto relacionado con la ignorancia o poco conocimiento acerca del Síndrome de Down.

Sentimos mucha incertidumbre, desconocimiento, temor. Temor a que S. no estuviera sano, que por dicha siempre lo ha estado, temor a no aprovechar bien el tiempo; para hacerle sus masajes, ejercicios y terapias.

Yo como mamá me preocupé por sacarlo adelante lo más pronto posible, tener los mejores doctores revisándolo por todo lado y los mejores profesores de estimulación temprana.

Conforme pasó el tiempo nos dimos cuenta que él podía hacer todo lo que mi hija mayor hace, solo que ocupa un poco más de tiempo para lograrlo. Nuestro miedo desapareció y ahora él ha crecido con los mismos límites y reglas que tenemos en la casa para nuestra otra hija.

Es una gran satisfacción verlo salir adelante, ver que es un niño feliz y todos nosotros una familia orgullosa.

\section{Participante 5:}

Cuando mi hija nació y me dieron la noticia que era una niña con síndrome de Down, me puse muy triste y lloré mucho, la enfermera me dio una lista de enfermedades que padecen estos niños, entonces yo deseaba que mejor se muriera porque yo estaba muy asustada, creía que la iban a operar a cada rato.

Gracias a Dios mi esposo estaba conmigo y me apoyó mucho y él que tenía conocimientos sobre estos niños me explicó cómo son y yo la fui aceptando.

Al otro día hablamos con una doctora y le pedimos que nos ayudara y explicara dónde la podíamos llevar y ella nos refirió a una institución de educación especial y la llevamos y asistimos a charlas y escuela para padres que nos ha ayudado mucho.

Mi hija ha salido adelante, es una niña muy capaz, muy independiente y ahora le doy gracias a Dios por tener una hija con Síndrome de Down.

Es notable cómo, en los casos anteriores, las emociones y sentimientos experimentados, dan paso a la búsqueda de redes de apoyo que fortalezcan a la familia y, prioritariamente, brinden las mejores oportunidades de desarrollo integral a los niños y las niñas nacidas con síndrome de Down. 
doi: http://dx.doi.org/10.15359/ree.19-1.17

URL: http://www.una.ac.cr/educare

CORREO: educare@una.cr

La incertidumbre y la preocupación, son características de la fase de la negación, estas emociones y sentimientos son parte del proceso de aceptación de la condición de recibir a un recién nacido con síndrome de Down. En las siguientes historias se ejemplifican, en un inicio, dichos sentimientosy emociones, para posteriormente dar paso a un proceso de aceptación de la madre hacia su hija.

\section{Participante 6:}

Quizás lo que más me preocupó cuando recibí la noticia de la condición de mi hija fue: ¿Tendré la capacidad y la fortaleza para sacarla adelante? ¿Podré ayudarle?... Me sentía confundida, triste muy temerosa y desanimada... ¿Qué podría ofrecerle? ¿La aceptaría el mundo?

Pronto comprendí que debía ser yo la primera en aceptarla tal y como es. Así recuperé las fuerzas y la alegría

Mi hija ha traído grandes y hermosas enseñanzas: gracias a ella estoy redescubriendo la vida y el amor.

A pesar de que Costa Rica se encuentra en transición hacia un paradigma de derechos (Palacios 2008), donde es esperable que a nivel social todos tuviéramos igualdad de oportunidades y de desarrollo, los padres y madres de familia que tienen un niño o niña recién nacido con síndrome de Down no suelen, en la mayoría de las situaciones, encontrarse con contextos abiertos, receptivos y estimulantes para la situación que viven. Pues muchas veces, a nivel contextual, se enfrentan con personas que utilizan lenguaje peyorativo y etiquetador, retrasando los procesos de ajuste y aceptación que vivencian las familias ante el nacimiento de un recién nacido, en este caso con síndrome de Down.

\section{Participante 7:}

9:00 am ¡Llegó la hora!

Lista mamá, va para sala de operaciones.

Mi corazón saltó de alegría, la esperábamos con tanta ilusión, ya habiendo pasado todo, desperté en sala de recuperación. Y mi hija ¿cómo está? Pregunté, ella está bien me respondieron. Pasadas las horas traté de ponerme de pie, quería ver a mi hija, dejé todo para la hora de la visita, quería darle una sorpresa a mi esposo, ya que todo me había salido excelente. Me senté a la orilla de la cama a esperar que pasara una dama voluntaria para que me trajera a mi hija. De pronto veo pasar una de ellas con un bebé en su cunita, llegó al mostrador y dejó al bebé en el pasillo. 
¡Hora de visita! Cuando veo pasar a la gente noto que todos pasan y vuelven a ver al bebé que habían dejado en el pasillo, escuché a más de una persona decir: jah pobrecita! Pensé, ¿qué tendrá ese bebé que toda la gente arruga la cara cada vez que lo ve?

Sigo viendo pasar a la gente, cuando de pronto me dice una dama voluntaria-mamá, su bebé ya se lo trajeron?

No, precisamente le iba a decir a usted que si me trae a mi hija. La veo que se va directo a la cunita del bebé del pasillo, lo trae y me lo pone a la orilla de la cama, donde me levanto y veo aquel bebé, pensé: : Por Dios, qué es esto, una mongolita!, mi rostro cambió y no pasó desapercibido. Me pregunta la dama voluntaria, ¿es su bebé?, mi respuesta fue no, no es, nada más para estar segura, usted puede leer la tarjetita en voz alta. Está bien, respondí, pero sepa que no es mía. Toméla tarjeta en mi mano y empiezo a leerla, cuando veo que dice mi nombre. "Jehová Dios, es mía, dije".

No tienen idea de lo que sentí, se me adormeció el cuerpo, no sentí más la operación y eso que me costó 45 minutos ponerme en pie debido al dolor, volviendo a la realidad le respondí a la dama voluntaria, sí, sí es mía. Suerte señora y se desapareció.

La tomé en mis brazos, la abracé y dije: qué te hice mi amor, qué te hice, todo es mi culpa, por mi culpa naciste así.

Sigo viendo a la gente entrar y a lo lejos veo a mi esposo, y no precisamente solo para peores, no sabía qué hacer, le ponía un gorrito a mi bebé, se lo quitaba, se lo volvía a poner, me sentía como loca, estaba desesperada, no hallaba que hacer, la pegué al pecho y no la solté más hasta que terminó la hora de la visita. Di gracias a Jehová cuando se fueron.

Después pregunté a las enfermeras: ¿ustedes no le ven algo extraño a mi hija?

No para nada, pero si se siente preocupada espere mañana a la pediatra a ver qué dice, qué me quedaba, esperar y aún así mi corazón no me engañaba, algo no estaba bien, no dormí esa noche, esperaba a la pediatra.

Cuandollególa horale pregunté: ¿usted podríaexaminaramihijaydecirmesilenotaalgoextraño? ¿Usted le nota algo diferente a su hija?, preguntó ella. Sí, le respondí. ¿Usted lo que quiere saber es si su hija tiene retardo? Sí señora, ¿no la está viendo que es mongoloide?, la tiró en la cama y me dijo vístala. La vestí, no sé ni cómo y me fui por el pasillo a buscar a una enfermera y cuando vi a una la abracéy lloré desconsoladamente pidiendo a mi Cristo que me despertara de esa pesadilla.

Sin embargo, con la ayuda de Dios y de mi esposo tuve fuerzas para luchar y salir adelante, él me guio y no sé cómo cuando me di cuenta ya estaba en la puerta de un aula de una institución de educación especial donde me esperaba un ángel, tan pero tan especial que gracias a su ayuda tres años después puedo decirles sin lágrimas ni dolor alguno: "que la discapacidad jamás la aceptaré, pero créanme que he aprendido a vivir con ella porque es parte de mi hija." 
doi: http://dx.doi.org/10.15359/ree.19-1.17

URL: http://www.una.ac.cr/educare

CORREO: educare@una.cr

La amamos tanto y se lo demostramos día con día y como padres orgullosos decimos que tenemos la síndrome de Down más linda del mundo y algo muy importante es que ya no siento miedo al decirlo. Somos felices con nuestra hija S. La madre agrega: "Esta anécdota es dedicada a Maritza Esquivel maestra de mi hija y para aquellas madres que piensan que no hay esperanza".

En la misma línea del caso anterior, donde la reacción externa ante el nacimiento de un bebé con síndrome de Down no está, precisamente, teñido de comprensión y aceptación, se comparte la siguiente historia de vida.

\section{Participante 8:}

Cuando me desperté de la anestesia y abrí los ojos, mi mamá estaba allí con el doctor y estaba Ilorando. Me dijo que mi bebé era síndrome de Down y tenía una malformación en el corazón. Yo lloré y sentí que le había fallado al mundo, a la sociedad y a mi familia al haber tenido un bebé que solo yo iba a querer. Luego pensé, qué pena que no me va a dar nietos y que siempre iba a tener que ser supervisada.

Me sentí muy abrumada por todos estos pensamientos negativos sobre el futuro de M. Fue muy duro cuando todas las mamás recibían a sus bebés y yo era la única que no podía tener a mi bebé conmigo, debido a que por falta de oxigeno necesitó estar en la incubadora un par de días.

Las enfermeras me veían con lástima y cuando las demás pacientes les preguntaban por qué no me habían dado a mi bebé, la respuesta era: "Es que ha esa señora le nació una mongolita y tiene el corazón muy malo, quién sabe para que viva".

Yo me la llevé para la casa el 26 de diciembre sintiéndome muy triste como si me hubieran dado un muñequito nuevo, pero roto. Un familiar me fue a recoger junto con mi mamá y comentó: "Porqué los doctores son tan idiotas y no le advierten a las mujeres maduras que esto podría pasar"

Después de muchos días el dolor cesó y leí mucho sobre el síndrome de Down, libros lindos, otros muy duros y realistas y todo esto.

Para toda la gente, que como yo y mi bebé no se dejó derrotar ante todas las dificultades, ha sido un regalo de Dios y no una casualidad genética".

Como se ha dicho anteriormente, son variados los sentimientos y emociones que despierta una noticia no siempre esperada. Inseguridad, temor y angustia, fueron algunos vividos por el padre que nos narra la siguiente historia de vida. No obstante lo dicho, cabe destacar también la importancia del apoyo contextual, de las redes de contención e información, de las cuales disponen los padres y madres de familia y que muchas veces se desconocen. 
ReVISTA Electrónica EduCARe (EdUCARE Electronic JOURNAL) EISSN: 1409-4258 VOL. 19(1) ENERO-ABRIL, 2015: 311-331

doi: http://dx.doi.org/10.15359/ree.19-1.17

URL: http://www.una.ac.cr/educare

CORREO: educare@una.cr

\section{Participante 9:}

Cuando el doctor me comunicó que mi hijo tenía síndrome de Down, yo sentíuna desesperación muy grande, sentí que el mundo se me acababa, no sabía acerca del síndrome de Down, luego el doctor me explicó...

Durante varios días sentía una gran tristeza en mi corazón, les pedí mucho a Dios y a la Virgen, que me dieran fortaleza para seguir adelante y poder darle a mi hijo lo mejor. Darle amor que es lo más importante.

Con el pasar del tiempo, vemos que con el trabajo constante, en coordinación con el apoyo de la institución de educación especial, él se ha desarrollado, lento en comparación con sus hermanas, pero con el logro de haber aprendido a hacer muy bien las cosas. Con la estimulación desde pequeño, vemos que ha logrado caminar, hablar y hacer oraciones para expresar sus sentimientos y sobre todo lo que lo rodea, a decir, qué le duele cuando está enfermo, a decir que tiene hambre y qué quiere comer, quizá lo más grande es que él es muy amoroso, decirme a menudo "papi te amo", ver la ternura que hay en sus ojos, la alegría que expresa al recibirme cuando llego de trabajar.

A los padres que inician esta tarea, lo más importante es aferrarse a Dios, pedirle con mucha fe que nos ilumine cada día para sacar adelante a nuestros hijos, con el fin de que ellos sean mejores y se desenvuelvan de tal forma que no sean una carga para nadie".

La última historia recopilada, nos presenta un recorrido por todos los sentimientos y emociones que vivencia una madre ante la noticia de la discapacidad de su hijo y cómo después, con el apoyo necesario, logra un proceso de ajuste y aceptación.

\section{Participante 10:}

Cuando A. nació por medio de cesárea yo me puse a llorar de emoción, lo vi tan blanco, macho, tan gordo que hasta chino lo vi, el médico creyó que yo me había dado cuenta que había nacido con síndrome de Down y me dijo que tenía que ser valiente, quererlo mucho y atenderlo, que aunque sea un hombrecito había que dejarlo llorar. Lo que él no sabía era que lloraba de emoción que había nacido bien ante un parto un poco difícil y un embarazo relativamente normal, en el que el médico nunca me dijo que el bebé tuviera problemas.

Cuando nació, el médico sí le dijo a mi esposo que el bebé había nacido con síndrome de Down, él se desmayó y se angustió mucho, estaba muy desubicado y no hablaba. Ya en el cuarto lo encontré llorando, aunque él siempre es muy preocupado, yo creí que lloraba de emoción porque todo había salido bien y de que era un varón, pero tampoco me dijo nada. Al día siguiente el doctor le dijo a mi esposo que yo no sabía lo del bebé. 
doi: http://dx.doi.org/10.15359/ree.19-1.17

URL: http://www.una.ac.cr/educare

CORREO: educare@una.cr

El doctor me dijo que el bebé tenía síndrome de Down y un soplo en el corazón, sentí un vacío tan grande, me sentía como que estaba soñando, cuando él me dijo ya no vi bien al bebé, lo vi diferente, le vi el pelo parado, sacaba la lengua, ahí lo vi como un niño "mongolito", lo único que se me vino a la mente fue pensar por qué a nosotros, si ninguno de los dos fumamos, tomamos licor, y además tratamos de comer lo más saludablemente posible y en ninguna de las dos familias había una sola persona con discapacidad. Lo único que quería era que la tierra me tragara, devolver el tiempo y no haberme embarazado o que Dios se lo llevara, pensé que Dios no existía, puesto que siempre había tratado de hacer las cosas bien y me mandaba un hijo con problemas.

Cuando el médico me habló del problema, también me dijo las enfermedades que les da a ellos: están bajos de defensas, que pueden padecer de leucemia, que con facilidad se les afectan los bronquios, que padecen de la tiroides, problemas del corazón y que si él estaba complicado habría que operarlo y muchos mueren ahí, que mi vida de ahora en adelante había cambiado por completo porque con él yo no iba a ser lo mismo.

Lloré muchos días reclamándole a Dios lo que había hecho, lloraba mucho encima del bebé, deseaba tener una varita mágica para quitarle lo que tenía. Tras de eso se encuentra uno con personas que le dicen también todo lo malo que tienen estos niños, que son una carga, que pobrecita y algunas veces expresiones hasta de familiares más allegados, cosa que lo hace sentirse a uno como en un túnel sin salida.

Empezamos a llevarlo al Hospital de Niños a fisioterapia, ahí vi muchos niños con enfermedades terribles, lloré mucho del impacto de ver aquellos niños casi sin movimiento, casi ni la mirada movían, mi esposo y yo lloramos mucho, y vimos que nuestro hijo no estaba tan complicado, que el soplo no necesitaba cirugía y que más bien tenía que luchar mucho para sacarlo adelante.

Días después fuimos a una Iglesia Católica en Cartago, había una oración muy larga delante del Nazareno, empecé a leerla y me senté, lloré y lloré, tras de eso la leí como cinco veces, y todas las veces lloraba desconsoladamente. Recuerdo que era muy larga y muy bonita, en una de sus partes decía: "Señor quítame la angustia que tengo, el dolor y el llanto y dame risa, alegría y gozo para enfrentar todas mis dificultades..."

Eso creo fue lo que más me hizo llorar por algo que ya estaba hecho, me puse en el lugar de mi hijo, y pensé si yo fuera como él no quisiera que lloraran por mí por ser así. De ahí en adelante me propuse buscar ayuda para que él sea una persona de bien, que si tiene síndrome de Down, sea una persona capaz de desenvolverse y que no sea carga para nadie. 
Revista Electrónica EdUCARE (EdUCARE EleCtronic JOURNAL) EISSN: 1409-4258 VOL. 19(1) ENERO-ABRIL, 2015: 311-331

doi: http://dx.doi.org/10.15359/ree.19-1.17

URL: http://www.una.ac.cr/educare

CORREO: educare@una.cr

Empecé a entender a Dios, me dio el hijo que más me convenía, durante el embarazo veía a veces personas indigentes, drogadictos durmiendo en la calle, muchos niños en las calles pidiendo dinero, con hambre y pensé en el momento que el médico me anunció que era un varón y se me vino a la mente que no quería que mi hijo estuviera nunca en una situación de esas, pensé mucho en tantos problemas sociales como las drogas y los homosexuales, cosas que me impactaron y angustiaron mucho en ese embarazo y no así en los anteriores. Siento que Dios me vio tan angustiada que lo dejó para tenerlo siempre conmigo.

De días de nacido empezamos a llevarlo a terapias particulares, al Hospital de Niños, mientras lográbamos un lugar en la institución de educación especial, no había día que no le pidiera a Dios que me ayudara porque a veces era difícil, ya que ellos demandan mucho tiempo, y gasto económico ya que a los ocho meses le dio neumonía.

Constantemente le pido a Dios que él se desarrolle de la forma más sana y normal que se pueda. Trato de hablarle normalmente, todo lo entiende.

Siempre fuimos constantes en las terapias, masajes, no dejo de darle gracias a Dios que logró caminar al año y ocho meses, alrededor de los 2 años y tres meses empezó a avisar para sus necesidades fisiológicas, hoy día habla bastante claro, hace oraciones comprensibles, hace preguntas, da quejas de las hermanas, acusa a la empleada, da quejas de los compañeros, tiene muy buena memoria de personas que deja de ver, sabe los números del 1 al 10, dice su nombre con apellidos, sabe los nombre de todos los familiares, sabe su edad, sabe al menos dos colores, Ilama las cosas por su nombre, le encanta bailar y cantar, es muy amoroso, cariñoso, charlatán, comelón y a menudo me dice "mami que linda es".

Hoy día él participa como cualquier niño de todas las actividades familiares, comemos juntos, compartimos las compras en el supermercado, la feria, las tiendas, lugares en los que siempre nos topamos con toda clase de personas, algunos evitan mirarlo cuando él los quiere saludar, personas que solo lo miran y lo siguen de mala forma solo para verlo cómo es, a como hay personas que lo ven e inmediatamente se identifican con él, lo abrazan, le dan un beso, le regalan algo o le dicen expresiones como por ejemplo: que guapo, él se pone feliz cuando alguien lo saluda, cosas que hay que saber sobrellevar de la forma más natural.

Tengo muy claro que es un niño con síndrome de Down, pero no es el fin del mundo, no es ningún castigo, carga, ni desgracia, como a veces hay personas que le expresan eso a uno. Lo que sí tengo claro es que la constancia y el apoyo que les podamos dar a ellos al igual que a cualquier hijo es no diferenciarlos, todos los hijos siempre necesitan de nuestro apoyo y en especial del amor del núcleo familiar. 
doi: http://dx.doi.org/10.15359/ree.19-1.17

URL: http://www.una.ac.cr/educare

CORREO: educare@una.cr

Hoy A tiene 4 años y seis meses, para nosotros es el tesoro más grande que tenemos, yo en especial estoy locamente encantada y enamorada de él, no sé qué haría si Dios me lo quita. Sus hermanas lo adoran y él se vuelve loco con ellas, ellas prácticamente son sus maestras en la casa, con él pintan, juegan, brincan, cantan, bailan, etc. Ellas saben que es un niño con discapacidad y lo apoyan en todo.

Todos estos años A. ha permanecido en una institución de educación especial, y hasta la fecha me he sentido muy apoyada, moral y académicamente, por terapistas y especialmente por las maestras y la directora, ellas nos han sabido orientar y seguir luchando con todos los padres de familia en marcha siempre hacia delante, ya que sin la ayuda de ellas la tarea no hubiera sido fácil, pues los logros obtenidos son por el trabajo especializado.

En lo personal nosotros no tenemos palabras para agradecer a ellas y a Dios toda la ayuda y el apoyo incondicional recibido, para tener el hijo que hoy tenemos, un hijo con mucha capacidad de desenvolverse, con mucho entusiasmo por aprender y que trata de hacer las cosas de la mejor manera.

Como puede notarse, son similares los sentimientos y emociones que vivencian los padres y madres de familia que enfrentan el nacimiento de hijos o hijas con síndrome de Down, y muchos de ellos y ellas han experimentado las fases de las que habla Campabadal (2007), hasta llegar a la aceptación de la condición de sus hijos e hijas y comenzar a buscar las mejores opciones para el desarrollo integral de cada infante.

Después de conocer el diagnóstico médico de síndrome de Down en sus hijos e hijas, e iniciar el proceso educativo mediante la incorporación a sesiones de atención con estimulación temprana, los padres y madres adquieren mayor conocimiento sobre la condición que presenta su hijo o hija, saben qué es el síndrome de Down, lo cual les permite entender que muchos de los sentimientos y emociones que vivencian, no son solo propios, sino también otros padres y madres los han experimentado.

El programa de estimulación temprana permite la integración activa de los padres y madres de familia en el proceso de atención de su hijo o hija con síndrome de Down, los padres y madres participan de las sesiones junto a sus hijos e hijas desarrollando, con la guía de la docente, las actividades propuestas para potenciar las capacidades de cada infante.

Resumiendo las emociones y sentimientos que denotan las historias relatadas, es posible señalar que se refieren a: culpa, impotencia, miedo, preocupación, dolor, tristeza, rechazo, incertidumbre, temor, desánimo, angustia, deseos de que el bebé muera, desesperación, desconocimiento, falta de información. 
No obstante lo dicho, es también rescatable que, en todos los casos, estas situaciones iniciales se ven también apoyadas por la información sobre el síndrome de Down, ya sea aportada por médicos, enfermeras, maestras de educación especial, o por iniciativa de los padres y madres de familia, quienes se abocan a la lectura y búsqueda de información sobre esa condición. De modo que posterior a ello, manifiestan reacciones caracterizadas por buscar metas claras, tratar de que el hijo o hija logre ser independiente y se integre a la sociedad, buscar ayuda profesional, leer sobre el tema, buscar ayuda médica y espiritual, entre otras.

Esta comprensión de no estar solos con la situación, de sentir que hay quienes les comprenden porque viven sus mismas angustias y preocupaciones permite que muchas de estas familias superen los primeros sentimientos y emociones y se aboquen a tratar de brindar a sus hijos e hijas, mejores opciones para su desarrollo.

Los estudiantes, gracias a estos programas de estimulación temprana, y a la comprensión y decisión de los padres y madres de familia, han logrado integrarse a precoces edades al sistema regular, rescatando la importancia del trabajo en equipo, en donde la familia juega un papel importante en el proceso educativo.

Los padres y madres de familia se convierten en el pilar para realizar un trabajo conjunto con el docente y poder potenciar las áreas del desarrollo: cognitiva, lenguaje, psicomotriz y socioemocional, facilitando experiencias significativas que les permitan a estos niños y niñas la adquisición de mayores destrezas.

Es importante señalar que esto les lleva a superar, poco a poco, muchos de los tabúes que la sociedad ha tejido respecto al tema de la discapacidad; el asistir a clases les facilita desarrollar mayor seguridad en el trabajo a realizar con el menor o la menor; se fortalece el vínculo afectivo entre el hijo, la hija y su progenitor; reduce las tensiones familiares ante la incertidumbre del qué hacer ante la condición del menor; pero, sobre todo, permite potenciar al máximo las capacidades de cada niño y niña desde edades tempranas, momento en el cual el cerebro es más receptivo y realiza mayores conexiones neuronales que benefician su desarrollo integral.

Estas historias de vida se constituyen, por ello, en motivación y en contención para aquellas familias que, en distintos momentos de su vida, pueden enfrentar situaciones como las descritas.

Se agradece a los padres y madres participantes el aporte brindado y su interés porque las historias por ellos y ellas vividas sean dadas a conocer como un medio para apoyar a otros padres y madres de familia que enfrentan el nacimiento de un hijo o hija con síndrome de Down y, mediante ellas, también les permita comprender y conocer sobre dicha condición de discapacidad y sobre las alternativas que están disponibles. 
doi: http://dx.doi.org/10.15359/ree.19-1.17

URL: http://www.una.ac.cr/educare

CORREO: educare@una.cr

\section{Conclusión}

Los resultados obtenidos mediante el trabajo con historias de vida de padres y madres de familia de bebés nacidos con síndrome de Down permiten concluir lo siguiente:

Son variadas las emociones y sentimientos que experimentan los padres y madres ante la noticia de un nacimiento de niños o niñas con síndrome de Down, caracterizándose la mayoría por la culpabilidad, temor, dolor, tristeza, rechazo, miedo, preocupación, falta de información, desesperación entre otros.

De igual manera, cobran vital importancia las participaciones de médicos, enfermeras y docentes de educación especial como parte de las redes de apoyo que brindan a padres y madres de familia información acerca del síndrome que presentan sus hijos e hijas y ello les permite acercarse a alternativas de fortalecimiento a edades tempranas del desarrollo, dentro de las cuales se encuentran las opciones de estimulación temprana.

Cuando el padre o la madre deciden iniciar la atención de su hijo o hija con síndrome de Down, a temprana edad, han tomado una gran decisión, la cual cambia su forma de percibir la discapacidad y la rutina familiar, ya que cuentan con mayor conocimiento sobre la condición del menor, deben acomodarse a un horario, realizar pequeñas tareas en casa y además continuar con la vida en familia; por ello, lo más recomendable es involucrar a todos los miembros del hogar en el nuevo reto: al educar y apoyar al menor, de esta manera, se podrá disfrutar de cada momento sin que la situación se convierta en difícil de manejar.

Una vez que la familia, junto con sus hijos e hijas, se incorporan a un programa de estimulación temprana, logran conocer más sobre la condición de síndrome de Down; entendiendo que este hace referencia a un accidente genético, no a una enfermedad, comprenden que cada infante aprende, pero de manera más lenta y que requieren de apoyo para desarrollar destrezas y habilidades para la vida.

Trabajar con padres de familia, en los primeros años de vida de un bebé con síndrome de Down ha sido una experiencia muy enriquecedora, el docente de educación especial debe convertirse más que en un docente especializado, en un ser con capacidad de escucha, de guía y acompañamiento a esos padres y madres $y$, aśí, juntos, avanzar con éxito en el proceso educativo del menor.

Si el padre, madre o encargado se siente motivado y acompañado, será más fácil iniciar dicho proceso, ya que reforzarán, desde el hogar lo visto en clase, de manera que los objetivos planteados en el campo educativo se lograrán a corto tiempo.

Se plantea el reto de proponer, en un segundo artículo, una guía de trabajo para padres y madres de bebés recién nacidos con síndrome de Down, que les permita complementar el trabajo de la escuela estimulándolos desde el hogar y así desarrollar al máximo su potencial desde temprana edad. 


\section{Referencias}

Barboza-Argüello, M. y Umaña-Solís, L. M. (octubre-diciembre, 2008). Análisis de diez años de registro de malformaciones congénitas en Costa Rica. Acta Médica Costarricense, 50(4), 221-229. Recuperado de http://www.scielo.sa.cr/pdf/amc/v50n4/3799.pdf

Campabadal, M. (2007). El niño con discapacidad y su entorno. San José, Costa Rica: EUNED.

Cruz, F., Camacho, J. S., Rivera, J.C. y Saborío, M. (junio, 1985). La trisomía 21: Estudio retrospectivo de 658 casos. Revista Costarricense de Ciencias Médicas, 6(2), 51-71 Recuperado de http:// www.binasss.sa.cr/revistas/rccm/v6n2/art6.pdf

De Narvaez, M. (8 de junio de 2008). Estimulación, definición y objetivos [Mensaje en un blog]. Recuperado de http://estimulacionydesarrollo.blogspot.com/2008/06/estimulacintemprana-definicin-y.html

Kawage, A. (2000). Los hijos discapacitados y la familia. México: Trillas.

Kozma, C. (1998). ¿Qué es el síndrome de Down? (Cap. 1). En K. Stray-Gundersen (Comp.), Bebés con síndrome de Down (2a ed., pp. 1-36). Estados Unidos de América: Woodbine House.

Palacios, A. (2008). El modelo social de discapacidad: Orígenes, caracterización y plasmación en la Convención Internacional sobre los Derechos de las Personas con Discapacidad. Madrid: CERMI. Recuperado de http://www.cermi.es/es-ES/ColeccionesCermi/Cermi.es/Lists/ Coleccion/Attachments/64/Elmodelosocialdediscapacidad.pdf

Pereira, Z. (2012). La mirada estudiantil hacia las características docentes. Las dinámicas interactivas, los rasgos docentes y el clima de aula universitario, analizados con un diseño de método mixto. España: EAE.

Real Academia Española (2012). Diccionario de la lengua española (22a ed.). Recuperado de http://lema.rae.es/drae/?

Terré, O. (2005). Estimulación y desarrollo. Santa Cruz, Bolivia: Formas.

\section{Cómo citar este artículo en APA:}

Esquivel-Herrera, M. (enero-abril, 2015). Niños y niñas nacidos con síndrome de Down: Historias de vida de padres y madres. Revista Electrónica Educare, 19(1), 311-331. doi: http://dx.doi.org/10.15359/ree.19-1.17

Nota: Para citar este artículo en otros sistemas puede consultar el hipervínculo "Como citar el artículo" en la barra derecha de nuestro sitio web:

http://www.revistas.una.ac.cr/index.php/EDUCARE/index 